\title{
A review of pharmacological effects of xylopic acid
}

\author{
Elizabeth N. Oge ${ }^{1}$, Ernest Obese ${ }^{2}$, Robert P. Biney ${ }^{2}$, Emmanuel Adakudugu', \\ Mary Agbenyeku $^{1}$, Silas A. Osei ${ }^{1}$, Maria B. Cassera ${ }^{3}$, Ana Lisa Valenciano ${ }^{3}$, \\ Emilio F. Merino ${ }^{3}$, Johnson N. Boampong ${ }^{2}$, Eric Woode ${ }^{4}$, Madison Adanusa ${ }^{5}$, \\ Elvis O. Ameyaw ${ }^{1 *}$
}

\author{
${ }^{1}$ Department of Biomedical Sciences, School of Allied Health Sciences, College of Health and Allied Sciences, \\ University of Cape Coast, Cape Coast, Ghana \\ ${ }^{2}$ Department of Pharmacology, School of Medical Sciences, College of Health and Allied Sciences, University of Cape \\ Coast, Cape Coast, Ghana \\ ${ }^{3}$ Department of Biochemistry and Molecular Biology and Center for Tropical and Emerging Global Diseases \\ (CTEGD), University of Georgia, U.S. \\ ${ }^{4}$ Department of Pharmacology, Faculty of Pharmacy and Pharmaceutical Sciences, Kwame Nkrumah University of \\ Science and Technology, Kumasi, Ghana \\ ${ }^{5}$ University of Cape Coast Hospital, Cape Coast, Ghana
}

Received: 18 February 2020

Accepted: 03 April 2020

\section{*Correspondence:}

Dr. Elvis Ofori Ameyaw,

Email: eameyaw@ucc.edu.gh

Copyright: (c) the author(s), publisher and licensee Medip Academy. This is an open-access article distributed under the terms of the Creative Commons Attribution Non-Commercial License, which permits unrestricted non-commercial use, distribution, and reproduction in any medium, provided the original work is properly cited.

\begin{abstract}
Xylopic acid (15 $\beta$-acetyloxy-kaur-16-en-19-oic acid) is a kaurene diterpene that can be obtained from various Xylopia spp. Xylopic acid has demonstrated several pharmacological activities in vitro and in vivo. The compound has shown promising effect as a potent analgesic, anti-inflammatory and anti-allergic agent. Xylopic acid is a CNS depressant and was able to ameliorate anxiety-like symptoms in mice in addition to its neuroprotective effects. Deleterious effects of xylopic acid on the reproductive system of mice have been well documented but extensive toxicity study detailing effect of the acid upon chronic exposure needs to be determined. Due to the heavy consumption of $X$. aethiopica fruits, it is recommended that the pharmacokinetics of xylopic acid be determined to ascertain the possible food-drug interaction that may occur when conventional drugs are taken together with foods containing xylopic acid.
\end{abstract}

Keywords: Xylopic acid, Pain, Inflammation, CNS disorders, Infections, Xylopia aethiopica

\section{INTRODUCTION}

Xylopic acid (15ß-acetyloxy-kaur-16-en-19-oic acid) is a kaurene diterpene usually obtained from the dried unripe fruit of Xylopia aethiopica (Dunal) A. Rich (Annonaceae) and other Xylopia spp. Scientific reports on its isolation and characterization dates as far back as $1968 .^{1}$ Xylopic acid has been reported to possess several pharmacological activities but has not yet received much attention in order to move to the next level of drug development. Again, some important scientific data such as its pharmacokinetic profile are clearly missing from literature. This review seeks to highlight the beneficial and safety profile of xylopic acid and identify the relevant research gaps for further research geared towards the full drug development of this small molecule.

\section{SOURCES OF XYLOPIC ACID}

Xylopic acid has been identified and isolated from fruits of Xylopia aethiopica, (Annonaceae), aerial parts of Wedelia paludosa D.C. (Asteraceae), fruit of Xylopia frutescens Aubl. (Annonaceae) and, Xylopia sericeae A. St. - Hil. (Annonaceae). ${ }^{2-4}$ Xylopia aethiopica can be 
found in Ghana, Nigeria, Benin, Brazil, Cameroon Ethiopia etc. and the content of xylopic acid in the fruit of $X$. aethiopica has been found to vary in the fruit of the plants in these countries. This implies geographic location and environmental factors affect xylopic acid content in the fruit of $X$. aethiopica. Example, fruit samples from Cameroon were found to have the highest average content $(0.7983 \mathrm{mg} / \mathrm{g})$ followed by Ghana $(0.5969 \mathrm{mg} / \mathrm{g})$, Nigeria $(0.5469 \mathrm{mg} / \mathrm{g})$ and Benin $(0.5302$ $\mathrm{mg} / \mathrm{g}){ }^{5}$ Quantification of the content of xylopic acid in the other plant sources has not yet been reported.

\section{CHEMISTRY OF XYLOPIC ACID}

\section{Physicochemical properties}

Xylopic acid is a whitish powder or crystal when isolated. It has other chemical names such as $15 \beta$-acetyloxy-kaur16-en-19-oic acid. The IUPAC name is 15-acetyloxy-5, 9-dimethyl-14-methylidenetetracyclo (11.2.1.0.0) hexadecane-5-carboxylic acid. ${ }^{1,10,4,9}$ The acid has a molecular formula of $\mathrm{C}_{22} \mathrm{H}_{32} \mathrm{O}_{4}$ and a molecular weight of $360.494 \mathrm{~g} / \mathrm{mol}^{6}$ The melting point of xylopic acid has been determined to be $260-261^{\circ} \mathrm{C}$. The acid is sparingly soluble in petroleum ether, DMSO, ethanol, methanol, ethyl acetate and soluble in chloroform. ${ }^{7}$ Other natural compounds closely related to xylopic acid are; kaurenoic acid, steviol, grandifloric acid, an epimer of xylopic acid, 15-oxo-ent-kaur-16-en-19-oic acid, xylopioxyde (16,17epoxy-15-oxo-ent-kauran-19-oic acid). ${ }^{1,2,8,9}$

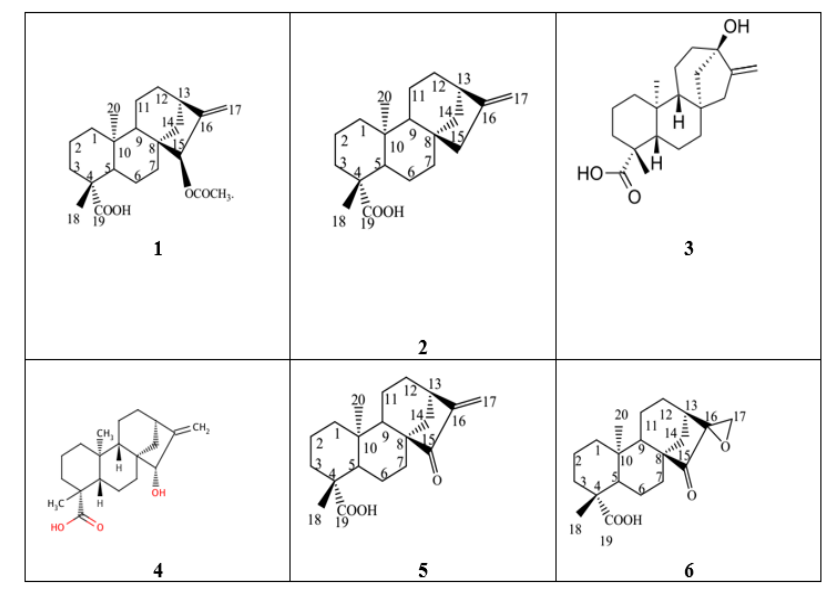

Figure 1: Natural compounds closely related to (1) xylopic acid, (2) kaurenoic acid, (3) steviol, (4) grandifloric acid, (5) 15-oxo-ent-kaur-16-en-19-oic acid and (6) xylopioxyde. ${ }^{1,2,8,9}$

\section{Derivatives of xylopic acid}

Novel derivatives of xylopic acid have been synthesized and characterized. ${ }^{8}$ The various derivatives, namely esters, amide and deacetylated analogues were synthesized in moderate to high yields (47.11-93.52\%) and characterized. The ester derivatives were: an ethyl ester of xylopic acid produced by acid catalysis, which appeared to be more polar than the xylopic acid starting material, a butyl ester; and a relatively low yield of benzyl ester.9,10 It was reported that deacetylation of xylopic acid initially produced the $\beta-\mathrm{OH}$ epimer, which upon prolonged heating slowly converts to the $\alpha-\mathrm{OH}$ epimer.

Santos and colleagues also synthesized and characterized a number of active anti-malarial derivatives by the reaction of xylopic acid with various compounds. ${ }^{2}$ Hydrolysis of the ester moiety of xylopic acid with potassium hydroxide, in methanol, under reflux, yielded a hydroxyl acid derivative. Esterification of the hydroxyl acid with methyl iodide yielded methyl ent-15 $\alpha$ hydroxy-kaur-16-en-19-oate. Sodium hydride and propargyl bromide reaction with the hydroxyl group of methyl ent-15 $\alpha$ - hydroxy-kaur-16-en-19-oate yielded propargyl ether.

Soh and colleagues first isolated xylopioxyde from the fruit Xylopia aethiopica. ${ }^{9}$ They successfully converted xylopic acid to 15-hydroxy-ent-kaur-16-en-19-oic acid, 15-oxo-ent-kaur-16-en-19-oic acid and two epimers of 15-acetoxy-16,17-ent-epoxy-kauran-19-oic acid through the oxidation of xylopic acid. The $\alpha$ and $\beta$ epimers demonstrated significant trypanocidal activity against $T$. brucei ( $\mathrm{ED}_{50} 127$ and $52 \mu \mathrm{M}$, respectively) with no detected cytotoxicity on mammalian cells (MRC-5 fibroblast).

\section{THERAPEUTICALLY BENEFICIAL AND OTHER ACTIVITIES OF XYLOPIC ACID}

Xylopic acid has been recognized to display diverse pharmacological properties with potential therapeutic benefits. It has been shown to possess anti-inflammatory, analgesic, anti-pyretic, anti-microbial, cytotoxic, antiallergic, neuroprotective, anti-malarial, anti-androgenic and spermato toxic properties.

\section{Anti-inflammatory and anti-oxidant activities of xylopic acid}

Xylopic acid demonstrated in vitro anti-inflammatory effect in a preliminary anti-inflammatory study using the protein denaturation model, and in vivo antiinflammatory assay. In addition, xylopic acid showed anti-arthritic property in the adjuvant-induced arthritis model in rats. The anti-inflammatory activity of xylopic acid was attributed to the modulation of proinflammatory markers namely histamine, serotonin, bradykinin and phospholipid/arachidonate pathways of inflammation. The compound also exerted an inhibitory effect on the expression of intercellular adhesion molecule-1 (ICAM-1) and cellular component recruitment in inflammatory processes present in acute inflammatory models. Other mechanisms reported to be involved in the anti-inflammatory effect of xylopic acid were inhibition of the serum expression of pro- 
inflammatory cytokines, IL-6 and TNF-alpha, in chronic inflammation. ${ }^{11,12}$

Ekuadzi and colleagues also reported the antiinflammatory effect of xylopic acid in an in vivo assay using the carrageenan-induced pleural inflammation model in mice. ${ }^{13}$ In the same study, they reported the ability of xylopic acid to increase catalase, superoxide dismutase, and glutathione levels and decrease lipid peroxidation level in reactive oxidative assays signifying the antioxidant activity of xylopic acid. This was corroborated with their findings that xylopic acid was able to prevent potential lung tissue damage by reducing significantly the signs of inflammation; neutrophil infiltration, oedema, and alveoli septal thickening in carrageenan-treated lung tissues.

Similarly, xylopic acid has been established to possess anti-colitic activity through the inhibition of reactive oxygen species. It decreased gross mucosal injury caused by acetic acid and decreased colonic epithelial expression of argyrophylic nucleolar organization regions. Xylopic acid in that study increased the activity of superoxide dismutase and catalase while decreasing the activity of myeloperoxidase and the expression of malonaldehyde confirming previous reports from other works. ${ }^{12,13}$

The anti-uveitogenic effect of xylopic acid has also been reported. ${ }^{14}$ Prophylactic administration of xylopic acid caused a significant reduction in vasodilatation of iris vessels, exudation, polymorphonuclear neutrophils in the aqueous humour of uveitic rats indicating its ocular antiinflammatory effects.

The anti-inflammatory activity of xylopic acid appear therefore to be mediated systemically and may signify the pharmacokinetic distribution of xylopic acid and/or its active metabolites into the various body compartments or body fluids.

\section{Analgesic activity of xylopic acid}

Xylopic acid demonstrated significant analgesic effect in various in vivo pain models including musculoskeletal pain, colic pain, neuropathic pain, neurogenic pain, thermal hyperalgesia, cold allodynia and inflammatory pain. Xylopic acid's antinociceptive effect was reported to be mediated through the opioidergic, adenosinergic, muscarinic cholinergic, NO/cGMP, serotoninergic and $\alpha_{2}$-adrenergic systems. ${ }^{15-17}$

In an attempt to identify alternate therapies for chemotherapy-induced neuropathy, xylopic acid was studied by researchers and was found to produce an effective therapeutic potential against paclitaxel-induced neuropathic pain, a type of pain difficult to treat clinically. ${ }^{17}$ The group also reported that xylopic acid possessed anti-allodynic and anti-hyperalgesic effects in vincristine-induced neuropathy. In addition, oral combinatory therapy of xylopic acid with pregabalin produced synergistic analgesic properties devoid of any significant toxic effects in a rat model of paclitaxelinduced neuropathic pain. ${ }^{17} \mathrm{~A}$ similar is bolographic study employing lower doses of xylopic acid and morphine or diclofenac combinations showed that xylopic acid demonstrates synergistic analgesic effects when co-administered with morphine and diclofenac. ${ }^{18}$

\section{Anti-pyretic activity of xylopic acid}

The ability of xylopic acid to reduce pyrexia has also been demonstrated by Boampong and colleagues. Xylopic acid demonstrated anti-pyretic effect on lipopolysaccharide-induced pyrexia in a murine model of pyrexia. The antipyretic property of xylopic acid was attributed to its ability to inhibit the production and/action of IL-2 and PG E2. ${ }^{19}$

\section{Antimicrobial activity of xylopic acid}

Numerous studies have shown the antibacterial and antifungal potential of xylopic acid and its synthesized derivatives. For instance, xylopic acid and its novel ester, amide and de-acetyl derivatives showed antimicrobial activity against Staphylocccus aureus, Staphylococcus pyrogenes, Bacillus subtilis, Escherichia coli, Pseudomonas aeruginosa and Candida albicans. ${ }^{20,21}$ Although xylopic acid has been reported to be active against $C$. parapsilosis, it was not active against fluconazole-resistant strains of $C$. parapsilosis. Xylopic acid in combination with kaurenoic acid however produced synergistic antifungal effect against fluconazole-resistant strains of $C$. parapsilosis. ${ }^{22}$

\section{Anti-allergic}

Xylopic acid has been shown to act as an anti-allergic agent. ${ }^{23}$ The compound provided anti-allergic effect in the passive cutaneous anaphylactic, systemic anaphylactic studies, pinnal inflammation reaction, LPSinduced septic shock, compound 48/80 - induced passive cutaneous anaphylaxis and clonidine - induced catalepsy models. The mechanism of action of xylopic acid in these allergic models was attributed to its ability to modulate the release of histamine and possible competitive $\mathrm{H}_{1}$ receptor blockade which would otherwise result in immediate hypersensitivity.

\section{Neuroprotective}

Excess reactive oxygen species (ROS) production due to the oxidation of dopamine can result in neurodegenerative diseases such as Parkinson's and Alzheimer's disease. Xylopic acid attenuated LPSinduced depressive-like symptoms by reducing immobility, increasing sucrose preference and enhancing social interaction. ${ }^{24}$ This activity is reported to be due to the significant reduction of oxidizing enzyme myeloperoxidase and reduced lipid peroxidation by xylopic acid whiles increasing the activity of superoxide 
dismutase, catalase and glutathione. ${ }^{12,13,24}$ From the above mechanisms, it was stated that xylopic acid potently increases brain derived neurotropic factor (BDNF) as well as reduced neurodegeneration indicating its neuroprotective property and further contribute to its myriad beneficial CNS effects.

\section{Antimalarial}

Xylopic acid possesses prophylactic and curative antimalarial properties in rodents which makes it an ideal antimalarial agent. It is reported to significantly reduce the effect of Plasmodium berghei infection similar to artemether/lumefantrine, the standard drug. ${ }^{19}$ The beneficial effect of co-administration of cryptolepine, a plant-derived alkaloid, and xylopic acid using $P$. berghei has been demonstrated. ${ }^{25}$ An observed synergistic antiplasmodial effect which did not have any significant deleterious effect on the kidney, liver and spleen was reported although high doses of the combinatory therapy showed significant effect on the testis. This effect on the testis could be accounted for by the reported spermato toxic effect of xylopic acid on the weight of the male reproductive organs, serum testosterone, testicular glycogen, cholesterol, protein and malondialdehyde. ${ }^{26-28}$ Again, cryptolepine has been demonstrated to be a potent cytotoxic and this could partly explain the observed deleterious effect of the combination therapy. ${ }^{29}$

Santos and colleagues however reported a low in vitro antimalarial activity for xylopic. In that report, the in vitro antimalarial activity of xylopic acid against $P$. falciparum W2 strain that is chloroquine-resistant and mefloquine-sensitive was determined using the parasite lactate dehydrogenase assay (pLDH) assay. ${ }^{2}$ The $\mathrm{IC}_{50}$ of xylopic acid was determined to be $>138.7 \mathrm{M}$ indicating its low potential of being developed as an antimalarial agent. Preliminary study employing chloroquine resistant Dd2 strain also showed that the compound was not active against this strain of $P$. falciparum. The difference in the in vitro and in vivo activity could be due to possible biotransformation of xylopic acid in vivo to produce active metabolites by human CYP450s. Xylopic acid has been postulated to be a substrate of liver metabolizing enzymes. It exhibits a biphasic effect by being an inhibitor of the enzymes at low doses and inducer at high doses. ${ }^{30}$ Thus, in the absence of liver metabolism in the in vitro assay xylopic acid may not be transformed into the active metabolite explaining the lack of activity. ${ }^{31}$

\section{Anti-androgenic and spermato toxic}

Xylopic acid has been shown to decrease testicular and epididymal weight; and serum testosterone levels. ${ }^{27,28}$ This indicates that xylopic acid possesses anti-androgenic and spermato toxic property. The mechanism of action is proposed to involve direct effect of xylopic acid on germ cells and other cells of the testis. ${ }^{29}$ Confirmatory research showed that the fruit extract of Xylopia aethiopica (which contains xylopic acid as its major secondary metabolite) reduced the weight of reproductive organs, serum testosterone; testicular glycogen, cholesterol, protein and malondialdehyde; whiles testicular superoxide dismutase increased. This may explain the mechanism behind xylopic acid-induced male infertility observed in rodents. ${ }^{26}$

\section{CNS effect of xylopic acid}

Xylopic acid has shown CNS depressant activity in vivo at lower doses. Higher doses above $300 \mathrm{mg} / \mathrm{kg}$ caused neuromuscular impairment and sedation. ${ }^{30}$ Research into epilepsy and anxiety using xylopic acid has seen some success. Xylopic acid has shown some evidence to be active in the management of convulsion by delaying the onset of pentylenetetrazole-induced seizures but neither reduced the frequency nor duration of seizures induced with PTZ. ${ }^{30}$ Xylopic acid may have some anticonvulsant effect depending on the pathophysiology of the convulsion. Further work is needed to confirm the possible anticonvulsant effect of xylopic acid by employing agents that induce convulsions via different mechanisms. Using mice and zebrafish models of anxiety disorders xylopic acid produced anxiolytic-like effect in the open field and elevated plus maze tests in mice and the novel tank test in zebrafish. ${ }^{32}$ Other CNS disorders such as a possible nootropic (memory, reactivity, motivation and learning) effect of xylopic acid have just recently been shown. ${ }^{33}$ Further research in this area may reveal additional benefits of xylopic acid as a drug for CNS disorders.

\section{SAFETY PROFILE OF XYLOPIC ACID}

\section{Cytotoxicity, genotoxicity and mutagenicity}

Although some terpenoids have been found to be genotoxic, cytotoxic and mutagenic, report on xylopic acid indicated that it devoid of genotoxic, cytotoxic and mutagenic activities. ${ }^{34}$ The $\mathrm{LD}_{50}$ of xylopic acid has been suggested to be above $1000 \mathrm{mg} / \mathrm{kg}$ in the Irwins test. This suggests xylopic acid does not cause observable physical toxicity and death when administered acutely. On the contrary, preliminary data from our laboratory indicates that xylopic acid destroys spermatozoa by decreasing sperm motility, sperm count and induces sperm death at $100 \mathrm{mg} / \mathrm{kg}$ in rats. Paradoxically, the same dose increases the sperm count. This points to the possible toxic effect of xylopic acid on the reproductive system in men. Acute, sub- acute and chronic toxicity studies on xylopic acid have not been done despite the extensive pharmacological works done on the acid. Lack of adequate toxicity data makes research on this compound far from complete and further works in this area is highly recommended. It is worth noting that xylopic acid is the most predominant active principle in the fruit of $X$. aethiopica. $X$. aethiopica is a spice globally used to prepare variety of cuisine. ${ }^{5}$ This implies all categories of people including pregnant women and children are exposed to both the beneficial and potential harmful 
effect of xylopic acid. It is important to caution men of child bearing age to avoid or reduce the consumption of the fruit of $X$. aethiopica due to the potential harmful effect on reproduction.

\section{CONCLUSION}

Traditional knowledge about $X$. aethiopica laid the foundation for exploring the pharmacological benefits of xylopic acid. To this end, xylopic acid has not been used clinically for diseases but has experimentally shown possibility to be used as an agent for inflammation, pain, allergies, CNS disorders, malarial and neuroprotection. Due to the heavy consumption of $X$. aethiopica (indirectly xylopic acid), the possibility of food-drug interaction should be investigated due to the possibility of xylopic acid inhibiting or inducing cytochrome P450s liver enzymes responsible for the metabolism of several drugs and xenobiotics. Drugs that induce or inhibit these enzymes present with important drug-drug interaction by decreasing the efficacy of the drugs or increasing the toxicity of the drug.

\section{ACKNOWLEDGEMENTS}

The authors are grateful to Fulbright commission (Fulbright African Research Scholar Program) and Education and Cultural Affairs of the U.S Embassy in Ghana, Dr. Meshack Agyapong, Ms. Francisca Frimpong, Ms. Elizabeth Obese, Ms. Adriana Biney and the technical staff at University of Cape Coast School of Pharmacy and Pharmaceutical Sciences.

Funding: No funding sources Conflict of interest: None declared

Ethical approval: Not required

\section{REFERENCES}

1. Ekong D, Ogan AU. Chemistry of the constituents of Xylopia aethiopica. The structure of Xylopic acid a new diterpene acid. J Chemical Society. 1968;3:3112.

2. Santos JO, Pereira GR, Brandao GC, Borgati FT, Arantes LM, Paula RC, et al. Synthesis, in vitro Antimalarial Activity and in silico Studies of Hybrid Kauranoid 1,2,3-Triazoles Derived from Naturally Occurring Diterpenes. J Brazilian Chemical Society. 2016;27(3):551-65.

3. Takahashi JA, Boaventura AMD, Bayma JC, Oliveira BA. Frutoic acid, a dimeric kaurane diterpene from Xylopia frutescens, Phytochemistry. 1995;40(2):6079.

4. Cavalcanti BC, Ferreira JRO, Moura DJ, Rosa RM, Furtado GV, Burbano RR, et al. Structuremutagenicity relationship of kaurenoic acid from Xylopia sericeae (Annonaceae). Mutation Research. 2010;701:153-63.

5. Alolga RN, Assanhou AG, Onoj J. Quantification of Xylopic acid and chromatographic fingerprint evaluations of the dried fruits of Xylopia aethiopica from four African countries. African J Traditional Complementary Alternate Med. 2018;15(3):18-26.

6. U.S. National Library of Medicine, National Center for Biotechnology Information. Available at: https://pubchem.ncbi.nlm.nih.gov/compound/494328. Accessed on 25 February 2019.

7. Ameyaw 2012, Thesis at http://dspace.knust.edu.gh/ bitstream/123456789/4557/1/Elvis\%20Ofori\%20Am eyaw.pdf.

8. Fetse JP, Kofie W, Adosraku RK. Ethnopharmacological, Importance of Xylopia aethiopica (DUNAL) A. RICH (Annonaceae) - A Review. British J Pharmaceutical Res. 2016;11(1):1-21.

9. Soh D, Nkwengoua E, Ngantchou I, Nyasse B, Denier C, Hannaert V, et al. Xylopioxyde and other bioactive kauranediterpenes from Xylopia aethiopica Dunal (Annonaceae). J Applied Pharmaceutical Sci. 2013;3(12):13-19.

10. Kofie W, Fetse JP, Adosraku RK. Synthesis and characterization of novel Xylopic acid derivatives. American Chemical Sci J. 2016;16(2):1-12.

11. Osafo N, Biney RP, Obiri DD. Aqueous ethanol fruit extract of Xylopia aethiopica and Xylopic acid exhibit anti-inflammatory activity through inhibition of the arachidonic acid pathway. UK $\mathrm{J}$ of Pharmaceutical Biosci. 2016;4:35-41.

12. Osafo N, Obiri D, Antwi AO, Yeboah OK. The acute anti-inflammatory action of xylopic acid isolated from Xylopia aethiopica. J Basic Clinical Physiology Pharmacology. 2018;29(6):659-69.

13. Ekuadzi E, Biney, RP, Benneh CK, Amankwaa BO, Jato J. Anti-inflammatory properties of betulinic acid and Xylopic acid in the carrageenan- induced pleurisy model of lung inflammation in mice. Phytotherapy Res. 2017;1-8.

14. Kyei S, Ameyaw EO, Koffuor, GA, Boampong JN, Woode E, Afriyie OO. Anti-uveitogenic effect of xylopic acid in Sprague-Dawley rats. European $\mathrm{J}$ of Experimental Biology. 2014;4(6):32-9.

15. Woode E, Ameyaw EO, Ainooson GK, Abotsi WKM, Kyekyeku OJ. Analgesic Effects of an Ethanol Extract of the Fruits of Xylopia aethiopica and Xylopic Acid in Murine Models: Possible Mechanism(s). Pharmacologia. 2013;4:285-300.

16. Woode E, Ameyaw EO, Gyasi BE, Abotsi WKM. Analgesic Effects of an Ethanol Extract of the Fruits of Xylopia aethiopica (Dunal) A. Rich. (Annonaceae) and the Major Constituent, Xylopic Acid in Murine Models. J Pharmacy Bioallied Sci. 2012;4:429-301.

17. Ameyaw EO, Woode E, Kyei S, Biney RP, Boampong JN. Anti-nociceptive synergism of pregabalin and Xylopic acid co-administration in paclitaxel-induced neuropathy: is bolographic analysis. Pharmacognosy J. 2015;7(6):363-8.

18. Woode E, Ameyaw EO, Abotsi WKM, Gyasi B. An is bolographic analysis of the antinociceptive effect of Xylopic acid in combination with morphine or diclofenac. Journal Basic Clinical Pharmacy. 2015;6:103-8. 
19. Boampong JN, Ameyaw EO, Aboagye B, Asare K, Kyei S, Donfack JH, et al. The curative and prophylactic effects of Xylopic acid on Plasmodium berghei infection in mice. $\mathrm{J}$ Parsitology Res. 2013;7:356107.

20. Kofie W, Fetse JP, Adosraku RK. Anti-microbial activities of Novel Xylopic Acid deriavatives. J of Advances Microbiol. 2019;14(1):1-6.

21. Yiadom BK, Fiagbe NI, Ayim JS. Antimicrobial properties of some West African medicinal plants iv. Antimicrobial activity of Xylopic acid and other constituents of the fruits of Xylopia aethiopica (Annonaceae). Lloydia. 1977;40:543-5.

22. Neto JB, Silva CR, Campos R, Nascimento FB, Sampaio LS, Silva AR, et al. Evaluation of synergistic effect of kaurenoic acid derivatives with fluconazole against strains of fluconazole-resistant Candida parapsilosis. Int J Current Microbiology and Applied Sci. 2015;4(5):68-79.

23. Osafo N, Obiri D. The fruit extract of Xylopia aethiopica (dunal) A. Rich. (Annonaceae) and its principal constituent, Xylopic acid, modulate inflammation. Thesis published at http://ir.knust.edu.gh/bitstream/123456789/8106/1/th e\%20fruit \%20extract\%20of\%20xylopia\%20aethiopic a\%20\%28dunal\%29\%20a.\%20rich.\%20\%28annonac eae $\% 29 \% 20$ and $\% 20$ its $\% 20$ principal\%20constitue.pd f; 2015.

24. Biney RP, Gyasi BE, Benneh CK, Woode E. Neuroprotective effects of Xylopic acid on lippolysaccharide induced neuroinflammation. Planta Medica. 2015;81(16).

25. Ameyaw EO, Asmah KB, Biney RP, Henneh IT, Agyei OP, Prah J, Forkuo AD. Isobolographic analysis of co-administration of two plant-derived antiplasmodial drug candidates, cryptolepine and Xylopic acid, in Plasmodium berghei. Malaria J. 2018;17:153.

26. Ologhaguo MA, Nwafor A, Datonye VD. Impairments in testicular function indices in male wister rats; a possible mechanism for infertility induction by Xylopia aethiopica fruit extract. Int $\mathbf{J}$ Reproduction, Contraception, Obstetrics Gynecology. 2015;4(1).
27. Alhassan A, Woode E, Amidu N. Anti-androgenic activity of Xylopic acid in orchidectomerized rats. J Medical Biomedical Sci. 2013;2(1):30-6.

28. Woode E, Alhassan A, Abaidoo CS. Effect of Xylopic acid on sex hormones and spermatogenesis in male rats. Al Ameen J Medical Sci. 2012;5(3):28297.

29. Ansah C, Mensah KB. A review of the anticancer potential of the antimalarial herbal Cryptolepis sanguinolenta and its major alkaloid cryptolepine. Ghana Medical J. 2013;47(3):137-47.

30. Biney RP, Mante PK, Gyasi BE, Kukuia KE, Woode E. Neuropharmacological effects of an ethanolic fruit extract of Xylopia aethiopica and Xylopic acid, a kaurene diterpene isolate, in mice. West African $\mathbf{J}$ Pharmacy. 2014;25(1):106-17.

31. Wisedpanichkij R, Grams R, Chaijaroenkul W, Bangchang NK. Confutation of the existence of sequence-conserved cytochrome P450 enzymes in Plasmodium falciparum. Acta Trop. 2011;119(1):1922.

32. Biney RP, Benneh CK, Kyekyeku OJ, Ameyaw EO, Gyasi BE, Woode E. Attenuation of anxiety behaviours by Xylopic acid in mice and zebrafish models of anxiety disorder. UK J Pharmaceutical Biosci. 2018;6:7-16.

33. Koomson AE. Effect of an Ethanolic Fruit Extract of Xylopia Aethiopica and its major alkaloid, Xylopic acid, on learning and memory: A pre-clinical evaluation from a neuropharmacological perspective (Doctoral dissertation, University of Ghana); 2018.

34. Cavalcanti BC, Bezerra DP, Magalhaes HIF, Moraes MO, Lima MA, Silveira ER, et al. Kauren-19-oic acid induces DNA damage followed by apoptosis in human leukemia cells. J Applied Toxicol. 2009;29(7):560-8.

Cite this article as: Oge EN, Obese E, Biney RP, Adakudugu E, Agbenyeku M, Osei SA, et al. A review of pharmacological effects of xylopic acid. Int J Basic Clin Pharmacol 2020;9:813-8. 